\title{
Labour Supply and Skills Shortages in Australia
}

\author{
IImiawan Auwalin¹, Alick Nyasulu², and Siwaporn Kittayaapinant ${ }^{3}$ \\ ${ }^{1}$ Faculty of Economics and Business, Universitas Airlangga \\ ${ }^{2}$ United Nations ESCAP \\ ${ }^{3}$ Ecnet Systems, Thailand
}

\section{Abstract}

Australia is facing a problem of skills shortage that might impact on human capital. This may lead to unsustainable economic and productivity growth. The problem is caused by a combination of factors, such as low fertility rate, an ageing population and restricted immigration policy in recent times among others. In order to address this problem Australian government applies some policies including increasing skill migrants, extending the retirement age, increasing women participation in labour market and so on. This paper discusses the Australian policies to address the skills

Corresponding Author: IImiawan Auwalin

auwalin@feb.unair.ac.id

Received: 10 February 2019

Accepted: 14 March 2019

Published: 28 March 2019

Publishing services provided by Knowledge E

(c) Ilmiawan Auwalin et al. This article is distributed under the terms of the Creative Commons

Attribution License, which

permits unrestricted use and redistribution provided that the original author and source are credited.

Selection and Peer-review unde the responsibility of the ICIEBP Conference Committee.

\section{G OPEN ACCESS}

\section{Introduction}

Australia's economic growth has been very strong in the past fifteen years. This growth has been possible as a result of reforms and sound macro-economic management. Despite such impressive growth, supply side constraints threaten long term growth prospects. Labour shortages are rampant and infrastructure bottlenecks are emerging as major threats.

From 1980-2005, Australian labour supply increased by 60 percent (1.9 percent per annum on average), and the economy was geared to the expectation of continue significant increases in labour supply, especially an increase in the number of younger skilled workers (McDonald and Withers 2008). The main drivers of labour supply growth are the full entry of baby boom generation into labour market and a huge increase in female labour force participation rates.

However, the trend has reversed in recent times, by 2006 the growth had fallen to 1.2 per cent per annum, and threatens future economic prosperity. There are many factors that are attributed to the decline in labour supply. One major cause is an ageing population that is retiring the workforce. Like most developed countries, Australia has 
an ageing population. The proportion of people aged 65 and over is expected to more than double over the next few decades, raising questions about how this will affect Australia's long term economic (PCA, 2005). People aged over 55 years have significantly lower labour force participation rates than younger people. A recent report by the Australia Productivity Commission suggests that as more people move into older age groups, overall participation rates are projected to drop to 56.3 per cent by 2044-45 from around current levels of 64 .

One of the consequences of the decreasing labour supply is the emerging of skills shortages. Currently, Australia is experiencing skill shortages that are broadening as it is covering more occupations and deepening for some occupations, as it is becoming more difficult to find suitable workers for some particular skills. The presence of skills shortages in Australia can be best reflected through a comparison of labour productivity and participation rates. In Graph 1 below, we show labour productivity growth as measured by GDP per hours worked from 2000 to 2006. A comparison is made of Australia against an OECD average. Since 2001 labour productivity for Australia has been outgrown by the OECD average. In 2001, the OECD labour productivity grew by $7.2 \%$ compared to Australia's $3.9 \%$. The trend remains the same between 2001 and 2003. However, in 2004 and 2005 labour productivity declines in Australia. Overall, OECD labour productivity in 2004 and 2005 rises sharply and peaks in 2005. In Australia, labour productivity registers a negative growth of $0.1 \%$. It slightly picks up in 2006 to $0.5 \%$ as OECD labour productivity grows by $6 \%$. Nonetheless, Australia labour productivity growth is well below OECD average.

Growth in labour productivity may either arise as a result of more efficient use of labour given other inputs or increased availability of other inputs for the same number of workers such as physical capital, human capital and intermediate inputs. However, Australia labour productivity has been declining and debate points to lack of skills in various industries.

\section{Literature Review}

In understanding the problem of skills shortages, it is worth to explore the concept of 'skill' itself. Shah and GivenNameBurke (2005) defined a skill as an ability to perform a productive task at a certain level of competence. In this regards, possessing a skill is required for a person to be able to carry out his or her task productively. In addition, skills are also associated its acquisition both through formal ways, such as education and training, and informal ways, including informal learning, practice and on the job 


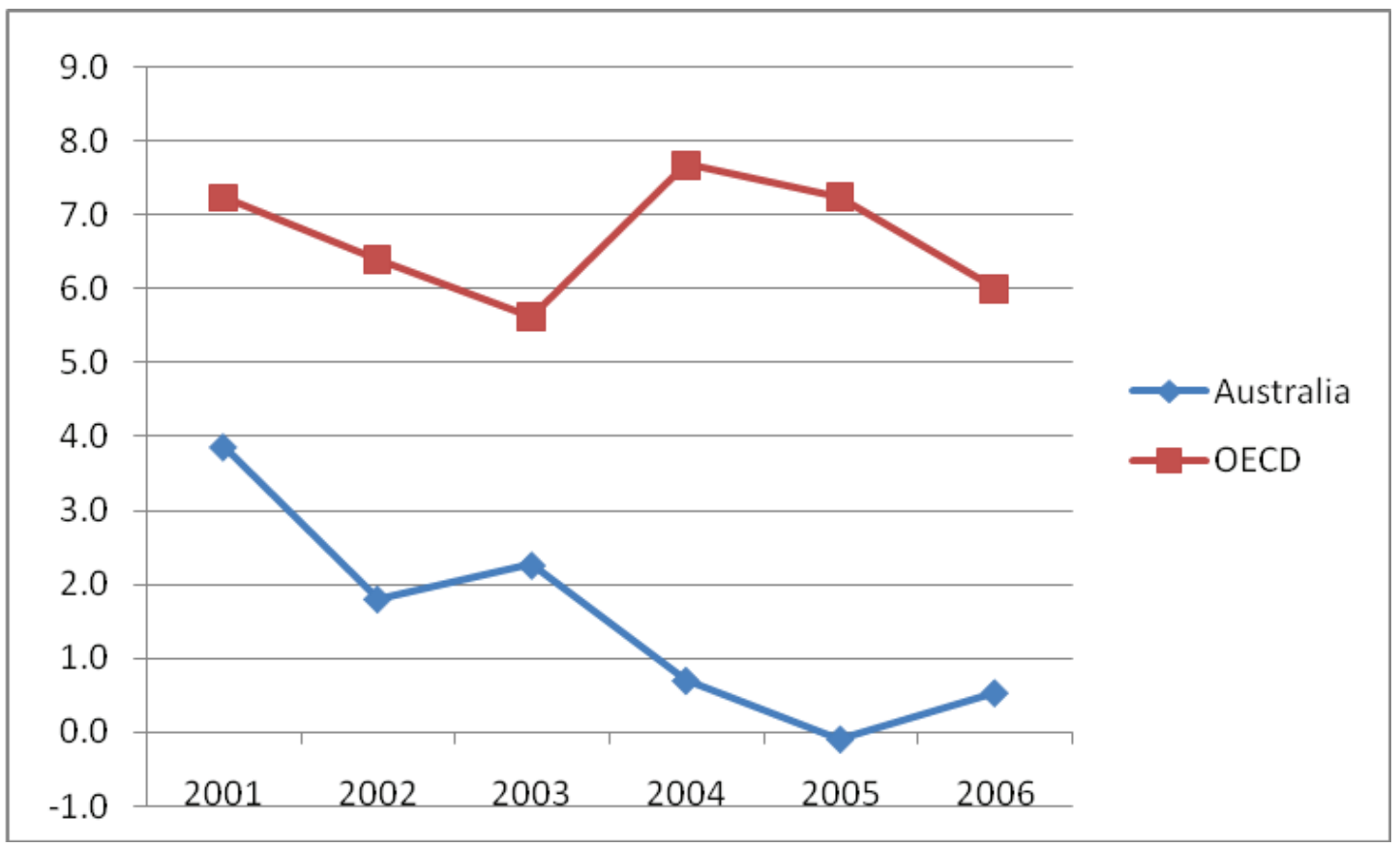

Figure 1: Labour Productivity Growth (\%) (Source: OECD Fact Book 2008).

experience (DEWR, 2005). The skills acquired by an individual, both from formal and informal ways, determine his or her ability to perform certain job.

In terms of the application of skills on different types of occupations, skills can be classified as either general or specific (DEWR, 2005). General skills are transferable and applicable across various types of occupations. These skills may include basic literacy and numeracy skills, interpersonal skills, working in teams and so on. In contrast, specific skills are more specific to certain industry or occupation. The skill shortage is especially related to the specific skills.

The skills shortages occur when the supply of workers with appropriate qualifications is not sufficient to meet the demand at the existing market conditions, especially the prevailing wages (Shah and GivenNameBurke, 2005). In other words, the labour market, the aggregation of all firms' demand and all individuals' supply of the specific skill is not in the equilibrium state. Theoretically, the market adjusts over time in several ways, including price and/or quantity adjustment or substitution with other types of labour, and eventually the imbalance clears. However, there is time lag before supply side adjusts to meet the demand side. During this time lags the skills shortages cause problem to the productivity and competitiveness of the economy. The lag might be longer as the long time required for skill formation in various skills. 


\section{Sources of Skill Shortages}

\subsection{The decreasing labour supply}

Labour productivity highlighted earlier gives summary indications about the state of skill shortage in Australia. Interestingly, over time the participation of women in the labour force has increased due to declining fertility rates. The daunting question is whether female participation is strong enough to overcome the effects of ageing in the long term. In Graph 2 below, we give a brief glimpse of labour force participation in Australia since 1986.

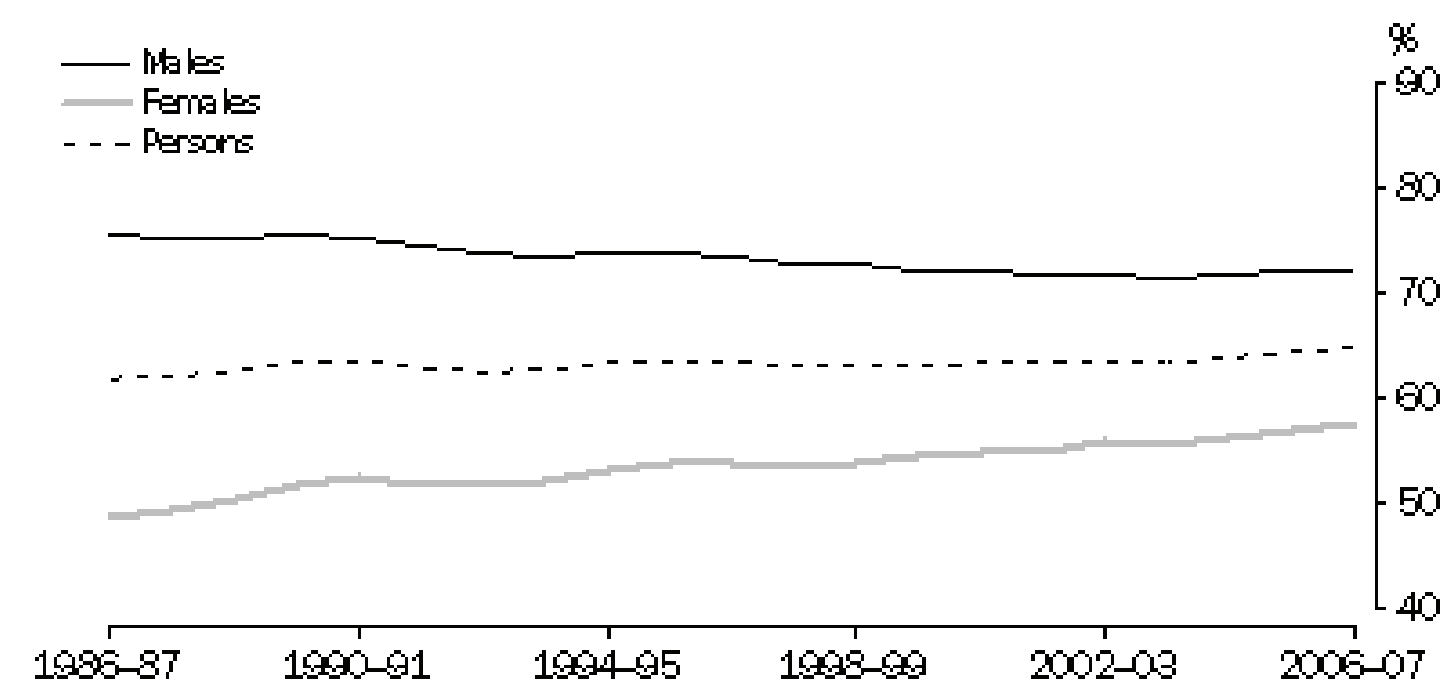

(a) Armal averages.

Source Latrour Foroe, Rustralia, Detailed' - Elextroxic Delivery (62910.55.003).

Figure 2: Labour Force Participation Rates.

Given outcomes in Table 2 above, in the last two decades the overall labour force participation rate moderately increased from $61.9 \%$ in $1986-87$ to $64.8 \%$ in $2006-07$. Female participation rate drove this increase. Female participation rate increased from $48.7 \%$ in $1986-87$ to $57.6 \%$ in $2006-07$. In contrast, the male participation rate decreased from $75.6 \%$ to $72.2 \%$ over the same period. There tends to be a convergence of male and female participation rates over this period.

Though female participation appears to rise, population dynamics give a worrisome picture and pose many threats to availability of necessary skills. In Graph 3, below, we give a quick snapshot of how Australian population has evolved.

As shown in graph 3, people aged 0-14 years represented $29.4 \%$ of Australia's population in 1956, while those aged 15-64 years represented $62.2 \%$, those aged 65 years and over represented $8.4 \%$ and those aged 85 years and over represented $0.4 \%$. 


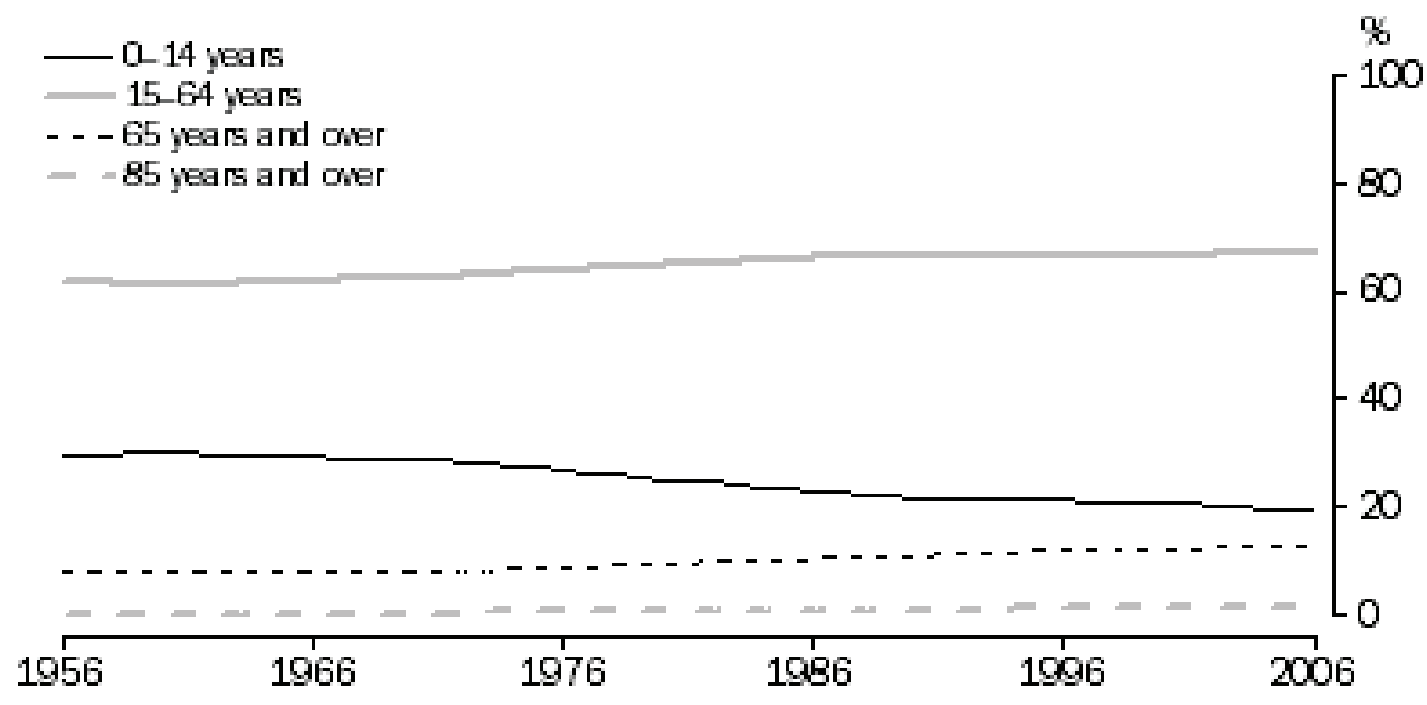

\section{Source: Austalian Historical Population Statis ics (3105. 0. 65.001); Population by Age and Sex, Australian States and Territories (3201.0.}

Figure 3: Trends in Structure of Australia Population.

Although Australia's population continued to grow since 1956, the proportion of children aged 0-14 years decreased to $19.6 \%$ by 2006 . In contrast, the proportion of people aged 15-64 years increased to $67.5 \%$ by 2006 and the proportion of the population aged 65 years or more increased to $13.0 \%$. The proportion of those aged 85 years and over increased fourfold to $1.6 \%$.

Similarly, a quick snapshot of Australian population pyramid that compares 1965 and 2006 indicates a possible labour supply problem.

The consequence of the combination of low fertility rates and decreasing mortality rates is the increasingly aging population. Graph 4 above shows the proportions of the population by age group and sex in 1956 and 2006, illustrating the ageing of Australia's population. In 1956, people aged 65 years and over represented $8.4 \%$ and those aged 85 years and over only represented $0.4 \%$ of Australian's population. In contrast, in 2006 , the proportion of the population aged 65 years or more increased to $13.0 \%$. The increasing ageing trend will still continue and in the next three decades there will be remarkably large increase of aged population as the post-war birth cohort or the "baby boom" generation enter the older ages (McDonald \& Kippen, 2001). While the population becomes increasingly ageing, the labour force growth is declining and threatening the sustainability of labour supply in Australia.

It is apparent that an ageing population is increasing as most people are living longer and fertility rates declining. This in the long run is likely to reduce the number of skilled workforce as the number of retirees surges. The ageing of Australia population has been 


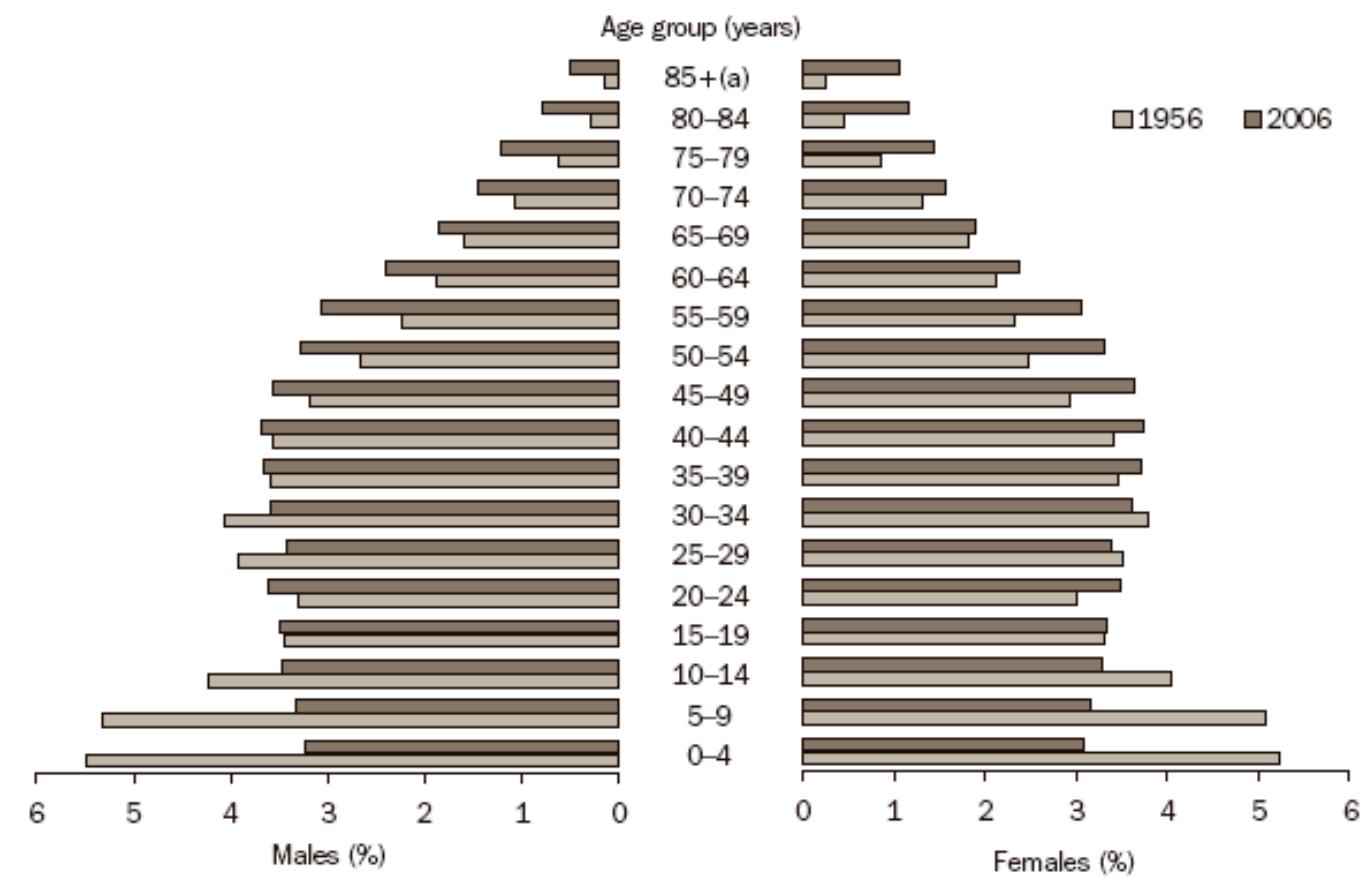

(a) The $85+$ age group includes all ages 85 years and over and is not directly comparable to the other five-year age groups.

Source: Australian Historical Population Statistics (3105.0.65.001); Population by Age and Sex, Australian States and Territories (3201.0).

Figure 4: Comparative Age and Sex Structure of Australian Population.

occurring ever since people started to acquire influence over fertility and mortality. As the incidence of deaths in all age groups has declined and the average number of births per women has fallen, the age structure has shifted profoundly. At Federation, the old were scarce. Less than one in 25 of the population were aged 65 years or more. Now, they comprise one in every eight Australians. By 2044-45, almost one in four will be aged 65 years and over. They will comprise around 7 million Australians (PCA, 2005)

According to the Australian Federal Government, ageing is occurring across Australia, with no jurisdiction escaping a significant shift in its age structure. South Australia and placeStateTasmania stand out as having the greatest concentrations of the old by 2044 45. This reflects their present above-average representation of the old and the tendency for migration patterns to disproportionately remove the young. The Northern Territory remains, by contrast, a relatively 'young' jurisdiction, as a consequence of its large Indigenous population and the fact that older Territorians often retire to other States.

The ageing population and the decreasing participation rate are likely contributing to the decreasing labour supply. As the number of labour decreases, the supply for effective labour that suit different types of jobs would fall as well, or in other word, the skills shortages would occur. In addition to the low labour supply, a skills shortage is also caused by the problem in labour market. According to Shah and Burke (2005) 
these problems are slowness in the adjustment of wages, slowness in the adjustment of supply and inadequate timely labour market information.

\subsection{The slowness of wages adjustment}

The relationship between price and quantity in Graph 5 gives a useful way to explain the importance of wage adjustment in the dynamics of skills shortage. Initially, the demand curve for a particular skill is $D_{1}$ and the supply curve at $S$. The equilibrium of the market is at point $e_{l}$ with wages We and supply of the particular skills at Qe. When there is an increase on the demand of particular skill from $D_{1}$ to $D_{2}$, the wages should adjust instantaneously to the new equilibrium wage of $W s$, otherwise the quantity of skills supplied will be less than the quantity demanded. In this case, the amount of the difference is between Qmax and Qe. Therefore, under this market conditions, a skill shortage will arise as the employers are facing difficulty to get the workers with the particular skills.

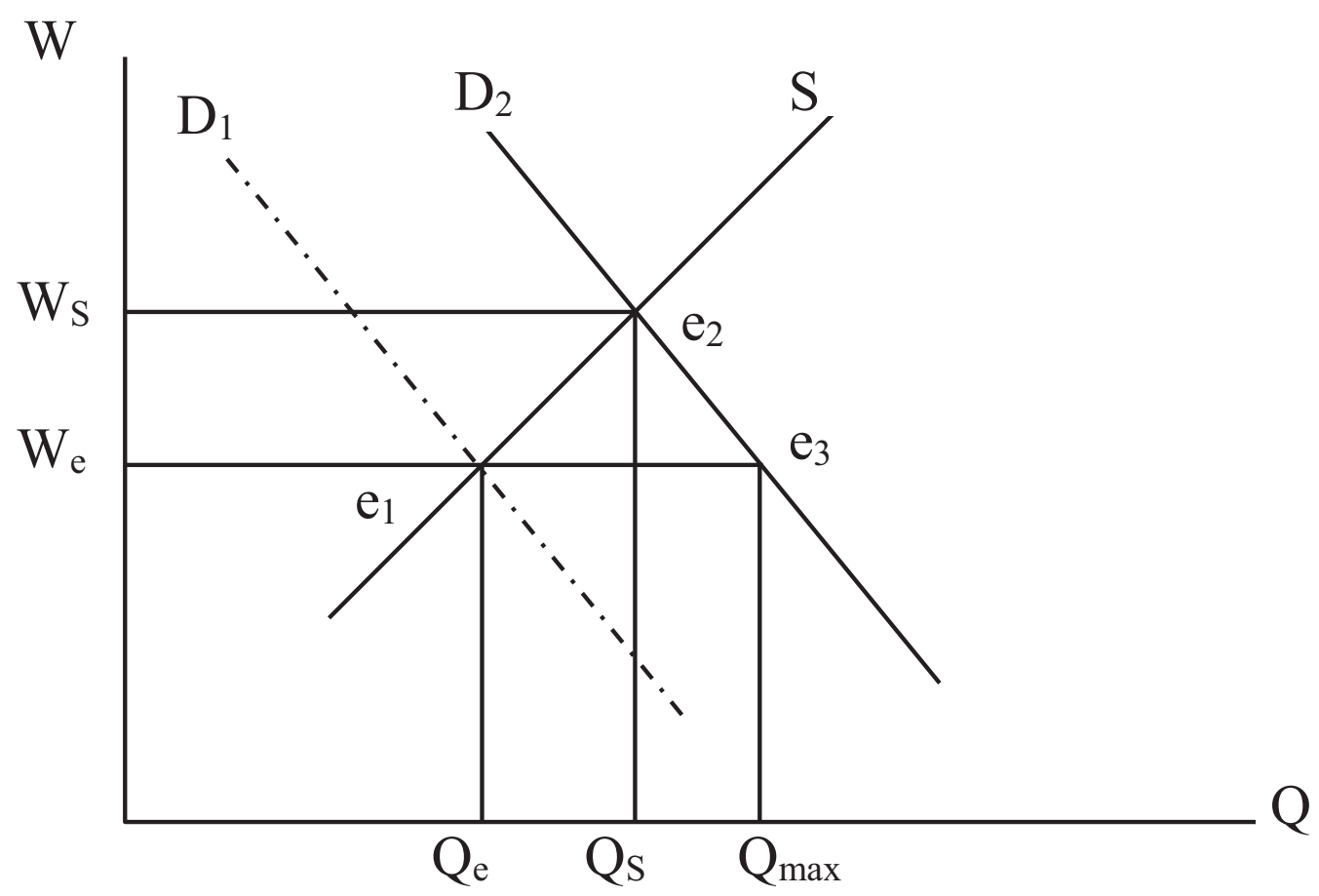

Figure 5: Market with an increasing demand for a particular skill (Source: Roy, Henson and Lavoie (1996)).

In practice, this type of wage adjustments usually takes time. There are some factors that reduce the market clearing function of wage adjustments and increase the wage stickiness are institutional and regulatory arrangements, such as contracts of employment between employers and employees, imperfect product market competition, lack 
of transparency of the market, wage controls and also social welfare provisions (OECD, 1994). In the case of Australia, the 'Accords' in the 1980s and early 1990s, which is the wages agreement within the industry, is another barrier to wages adjusting in the labour market (Shah and Burke, 2005). The accords emerges as the employers reluctant to offer higher wages to attract new recruits because they worry that higher wages for new worker will affect the salaries of the existing workers. In this situation, the firm may provide in-house training either to the existing low skilled employees in the firm or to the new entrants without the required skills to prevent wage increase.

Besides the slowness of wages adjustment, skills shortages can also take place when the equilibrium wage for a particular skill is below some minimum level (Roy, Henson and Lavoie, 1996). In this case, the minimum wage could represent the wage equivalent of public welfare benefits payments. Graph 6 describes one of the situations usually took place in low-skilled occupations. The initially demand is $D_{1}$ with equilibrium wage of We, but no worker in the existing labour market is willing to work at this wage because it is below the minimum wage of $W m$. In this case, employers will experience skills shortages. If employers are allowed to hire workers from outside the country's labour market, who do not mind the wage below the socially acceptable minimum, the supply curve shifts down to $S_{2}$, and new equilibrium is achieved at $e_{1}$.

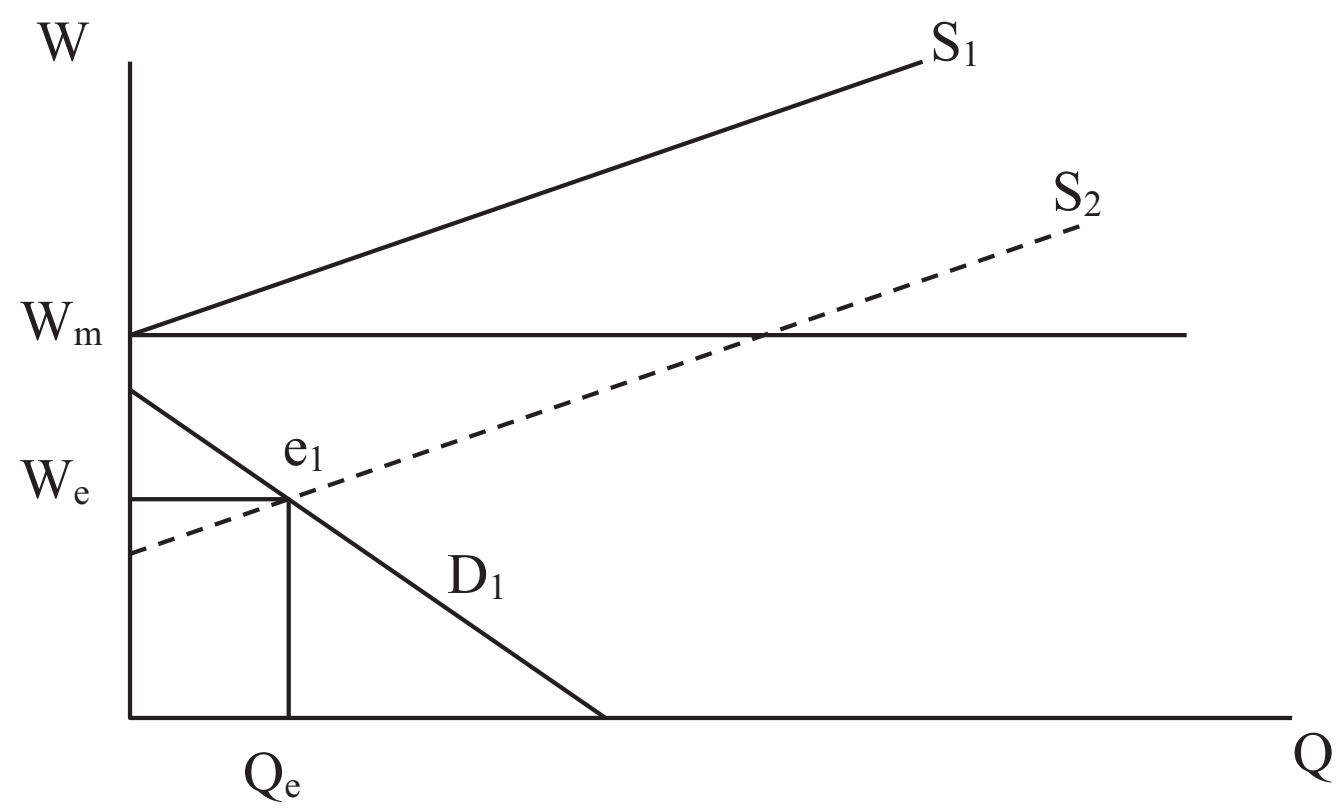

Figure 6: Market with equilibrium wage below a certain minimum (Source: GivenNameRoy, SnHenson and Lavoie (1996)). 


\subsection{Slowness in the adjustment of supply}

As skills formation takes some reasonable time, the adjustment of the supply of certain skills would take time as well. In practice, educational and training institutions are slowly in adjusting to the need of particular skills that are in shortage by offering places for particular courses (Shah and Burke, 2005). In addition, this problem will be worsening if the offered places are not attractive enough to the students. Under this situation, market clearing mechanism would work slowly and therefore the skills shortages would become persistent overtime.

\subsection{Lack of labour market information}

The existence of reliable labour market information to firms, households and education planners is important role to create an efficient labour market (Shah and Burke, 2005). The absence of reliable and in-time labour market information will make market adjustment to be slow and certainly longer the duration of skill shortages. In this case, the time lag is worsen by the required time for information of new opportunities to flow to relevant workers and the time taken by workers to take those opportunities.

\section{Consequences of Skills Shortages}

The decrease in labour supply will eventually cause difficulties for the economy in Australia in the near future. In the past Australia has never experience falling labour supply. In the past 30 years, there has been steady to rapid increases in labour supply from the baby boom generation entered the labour force and from the increased woman participation in the labour force (SnMcDonald and Kippen, 2001). However, the current labour force will eventually enter the retirement age and without sufficient labour supply there will be potential problems for the economy.

As shown in the beginning of this paper, one of the obvious effects of decreasing labour supply is skills shortages that affect the productivity growth. For a given labour productivity growth rate, the effect of population ageing and reduced fertility rates on labour supply is to slow Australia's economic growth over the coming decades. GDP per capita growth rates are projected to fall steadily over the period to around 2025 , with a partial recovery thereafter (PCA). The dip mainly reflects the ageing and withdrawal of the baby boomers from the labour force. GDP per capita growth is projected to slump to around 1.25 per cent a year by the mid 2020s - roughly half its rate in 2003-04 and 
one-third lower than without ageing. The longer run prognosis for economic growth per capita of 1.75 per cent a year reflects the fact that labour supply growth per capita in a stable population will be close to zero, so that growth only depends on the underlying rate of labour productivity growth.

Skills shortages will certainly affect the supply side of the economy. Shortages could lead to under-utilisation of capacity and accordingly reduced production (Shah and Burke, 2005). Furthermore, if the employers are responding to the difficulty of getting required workers by offering higher wages in ways that do not match productivity then this will lead to higher inflation. Another effect of bidding up wages in times of shortages is the faster circulation of existing workers supply between employers, therefore making employees retention more difficult and reducing the productivity of the involved employees.

In firm level, the present of skills shortages would make the firms to be less competitive. The decreasing competitiveness is especially coming from the increased recruitment and operating costs, reduced productivity, and constraints on business investment, development and expansion (DEWR, 2005). The following Graph 6 describes the effects of different skills level of new worker on firm's productivity, in particularly the figure show the importance of skilled worker who can quickly achieve a profitable level of productivity for the firm.

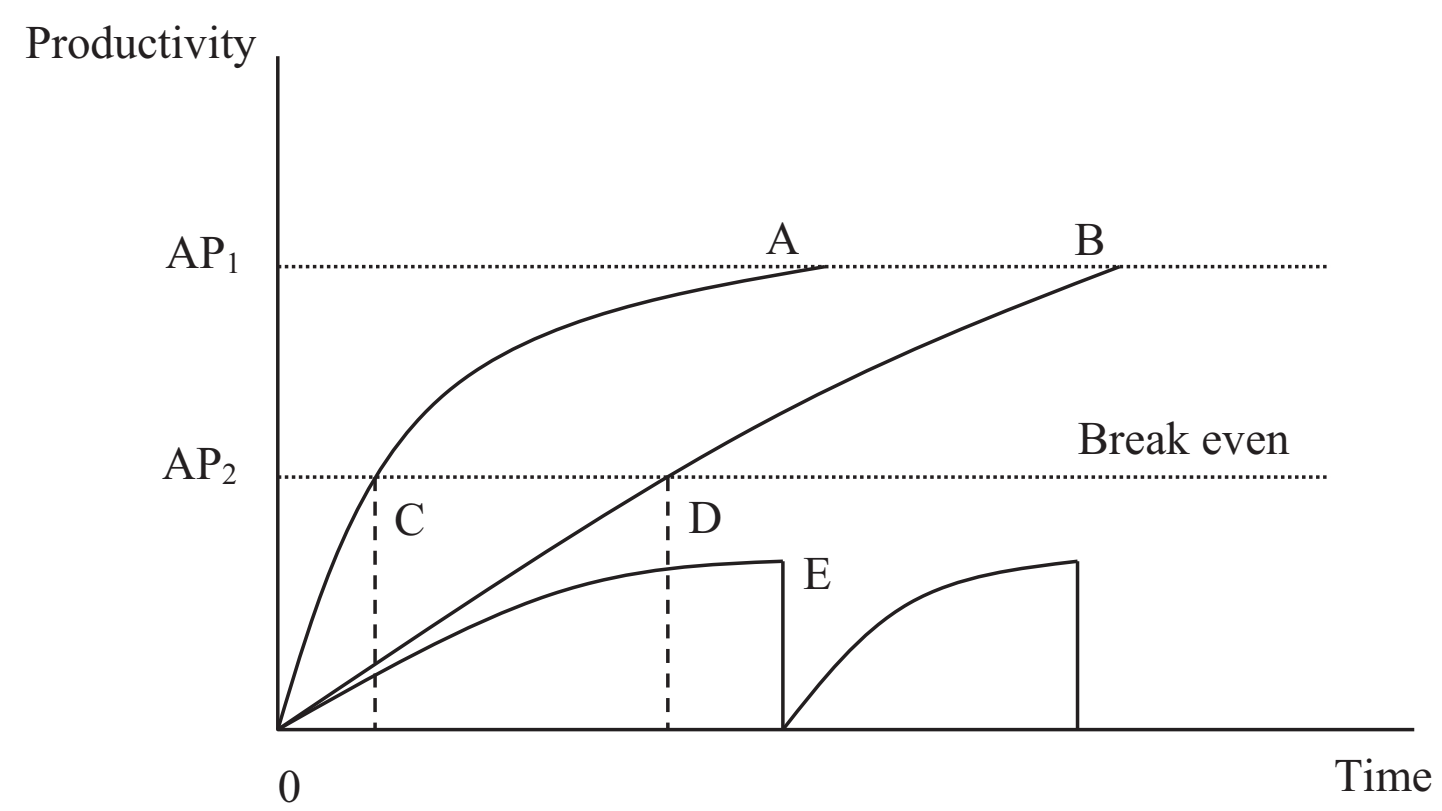

Figure 7: Skills shortages and productivity concerns of firms (Source: Mitchell and Quirk (2005)).

In Graph 6, $A P_{1}$ is the average productivity of the firm's workforce and $A P_{2}$ represents the productivity below which the worker's contribution to the firm's revenue equals the 
cost of employing the worker. In this case, it is assumed for the plant as a whole there are constant returns. In the beginning, the levels of productivity of all new workers are 0. Curve OA represents a new worker who has the required skills to perform the required work, quickly exceed the break-even level and reach the average productivity of the firm. While, curve placeOB characterize a new worker with lower skills or who more slowly acquires the skills needed to achieve average productivity over time. Curve OE represents the workers with lack of required skills or unable to acquire the needed skill in a reasonable time-frame. The OE curve describes the situation where one new worker after another is fired or quit before achieving break-even level of productivity.

Based on the condition described in Graph 6, firms would certainly look for the OA worker. If the firm employs the OB workers, the firm will have to experience a period of low productivity for some time until placeOB worker reach $A P_{1}$. While if the firm employs a series of short-lived workers as depicted by OE worker would mean dead loss to the firm (Mitchell and Quirk, 2005). However, in the present of skill shortages, firms would likely find difficulty to get the OA worker. Therefore, in the longer term, where skill shortages continue to exist, the firms may possibly adapt their operations to a lower skills base or occupations, so that they may not achieve their full growth potential (DEWR, 2005). In a situation where the skills shortages occurs nation wide, this would certainly reduce the competitiveness of the country.

\section{Policy Measures to Skill Shortages}

To cope with labour shortage, government must introduce potential policies to support labour participation in the market, resulting into increased productivity and economic growth. Some of the policy measures that are currently being used include conclude and evaluate the interesting and effective government policies, which are extending retirement age, increasing women labour force participation, and raising fertility rate. These can faster economic growth, growth of working age labour supply mitigating specific labour shortages, and increasing equity

Since ageing is the outcome of demographics, it might be thought that population policies could significantly solve it. However, such policies have some limitations. For a start, plausible changes in the total fertility rate and in net migration levels make relatively small differences to Australia's age dependency ratios (PCA, 2005). In any case, there is broad evidence that fertility rates are not very sensitive to policy and it is hard to devise measures that do not provide substantial and tax-inefficient transfers to people who were going to have children anyway. As well, any reversal of declining fertility 
would initially increase the aggregate dependency rate, with adverse implications for per capita labour supply growth, economic growth and accumulated fiscal gaps in the initial decades.

\subsection{Migration}

Increases in net migration are likely to be more amenable to policy action, since Australia is a small country and there are queues of willing migrants. Increases in net migration can partly reduce the fiscal pressures associated with ageing and low fertility rates, and could help to overcome some skill deficits. Migration is particularly important, not only to increase the absolute size of the population, but also to cover the labour demand that would likely unable to be fulfilled only by increasing participation rates. Migration is also bringing various benefits to the host country. The area receiving the migrants are most likely gaining benefits from low wages, utilisation of unused resources, and spread of new technology spread. Furthermore, if some of the migrants decide to settle permanently, the host areas will also likely to benefit the additions to physical capital (Miracle and Berry, 1970).

Under the current migrant policy, there are a number of visa sub classes allowing skilled migrants to live and work in Australia. Many of these visa sub classes are sponsored by certain regions or states, and oblige the applicants to work at least for two years in a designated regional area (BRTE, 2006). All skilled migrant applicants who have particular skill listed in the Department of Immigration and Multicultural Affairs (DIMA) Migrant Occupations in Demand List (MODL) obtain bonus points in their visa application process.

However, migration has a much bigger impact on population numbers than on Australia's age structure, which raises issues of congestion and sustainability. A focus on skilled migration could yield a bigger payoff. But migration targets for skilled labour may be difficult to achieve in the future, with other ageing countries competing for skilled migrants and with the potential for greater future emigration of skilled Australians.

In addition, the time lag is another problem of migration policy to solve skill shortages (Shah and Burke, 2005). The time lag occur as the moment a particular skills shortage took place and identified to the moment when the first migrants with those particular skills arrive can take fairly long time. Furthermore, the impact of immigrant is only covering limited areas as around 83 per cent of immigrants settle in major cities (BRTE, 2006). 


\subsection{Increasing labour force participation}

Increasing labour force participation is the key to addressing skill shortages. The declining labour force growth in Australia is partly due to decreasing labour force participation rates, particularly among young people and the elderly. A large proportion of young people are out of full-time labour force due to extension of education driven by the need to obtain higher skills. On the other hand, low participation rate of men aged 55 years and older is generally attributed to early retirement policies put in place in the 1970s (McDonald and Kippen, 2001). Early retirement policies were implemented to attract a large number of baby boom generations to enter the labour force (Gruber and Wise, 1997). However, at present time the policies would likely cause labour shortages as the baby boomers enter the retirement ages and the current labour supply are not sufficient to replace them. Therefore, in this regards, increasing the labour force participation of men at older age is a potential way to increase the labour force.

In order to keep the men aged 55 years and older in the labour force, the incentive to keep working should be better than the incentive to withdraw. In this regards, while in some states the changes to reverse early retirement trend has begun in the end of 1990's, in Australia as a whole the Commonwealth government has just begun to develop a comprehensive strategy on the employment of older worker in 2001 (Taylor, 2002). The process to replace the previous incentive to withdraw earlier from labour force by the incentive to remain in the labour force requires substantial political consideration as it likely to involve a reduction of expected retirement entitlement. Therefore, it may take a considerable time in order to apply the strategy nationally.

Increasing labour force participation of women is another applicable approach to increase labour supply. The approach already applied in many developed countries and evidence suggests that in the past three decades, labour supply has expanded due to increased women participation in the labour force (SnMcDonald and Kippen, 2001). Furthermore, there is potential in most developed countries, including Australia to further increase women participation rates. However, it is necessary to consider the reverse impact of increasing women participation on the fertility rates. Increasing fertility rates is important for the long-term labour supply growth.

It appears that increasing participation rate would less likely be able to match the growing labour demand. The number of labour force generated from increasing participation is likely to be small compared to the existing labour demand (SnMcDonald and Whiters, 2008). Increasing Australia's aggregate labour participation rate could raise Australia's future labour supply growth rates. The fact that Australia's present rate 
is only in the middle ranking of OECD countries suggests this is a viable objective. New Zealand, for example, has a significantly higher aggregate participation rate, a reflection of a different policy mix. Policies that discourage premature retirement and overcome obstacles to work could be effective in stimulating Australia's labour participation rates. They could also generate significant savings in social welfare payments, such as reduced outlays on disability support pensions.

\subsection{Raising fertility rate and family benefits}

There is additional instrument to increase labour supply. In the examination, Wooden (2004) has concluded that the major way to encourage women to have more children is to subsidy mothers' income, such as subsiding the cost of child care services. Furthermore, government may encourage parents by providing funded services or developing a quality assurance system. Given that women participation in the labour force is increasing, fertility issues are still critical for long-term labour supply as a population gets older.

However, it is imperative to relook at a possible policy crash. If women are encouraged to work, most of them may decide not to have children and consequently deprive the future of much needed labour force as they grow old. Declining fertility is a phenomenon of development but it does not mean nothing can be done. Work place regulations like a paid maternity leave are likely to encourage families to have more children plus subsidized child care costs. Consequently, increased fertility ensures that there is a sustainable future labour force. A combination of other policies in current period would then cover possible productivity shortfalls that arise out of women on maternity leave. This mainly would be taken over by policies that encourage effective labour supply like adoption of modern technologies and skills training for existing workers.

Although, these 3 policies can help to address labour shortage by increasing the number of labour force participation, there is still a questionnaire whether adopting these policies can increase aggregate labour supply. Evaluating the relationship between the second and the third policies, the government must decide to introduce only one of them. If government decide to increase labour supply by raising women participation rate, the third policy has to cancel, because the more women participation rate, the less probability for women to have more children. In addition, these 3 policies try to increase only the number of workers in labour market. This may not address the skill shortage problem, because although the number of labour has increased, it may still not match the job vacancies in labour market. Therefore, there are insufficient workers to meet the 
demand within domestic production. For these reason, the best government policies is to increase the effective labour supply, not just raising the number of labour force participation.

To raise the number of effective labour supply concentrate not only on the number of workers, but also focus on the quality of labour force, which match the employers' requirement. There are 3 core policies for addressing skill shortage, which are improving education attainment, adding training programs, investing in technologies, and allowing migrants to work without any entry barriers.

\subsection{Education, skills training and worker capacity}

Health and education are crucial contributors to human capital, changing the bundle of skills, knowledge and abilities of each individual. Human capital is an important factor to drive the productivity and meet the labour demand. Many studies confirm the importance of health care for human development. Government can improve people capacities by subsidizing and providing health care services for people to easily access.

Improvements to education and training aimed at equipping more people with the skills require participating in the labour market. Such development targeted on literacy and numeracy, further education, technical skills and adult learning. These can be achieved by funding and providing training program for workers in order to improve labour forces' abilities to work, especially in the available jobs.

\subsection{Investing in technologies}

Technological innovation is another key instrument to cope with labour shortage. Although the number of labour force participation rate does not increase, adopting new technologies can produce the same amount at a lower labour force or it mean that the producers can use the same number of workers, while they can get higher outputs. This generates country to become more productive similar to raising the number of labour supply. Investing in technologies increases effective labour supply. By using existing workers technology adoption enhances their skills and leads to efficient and less costly production techniques. As a consequence, introducing new technologies can help to cover skill shortage in available position. This policy can address the problem faster than increasing the labour force participation, because both need government budget to achieve, while investing new technologies spend less time to deal with skill shortage. 
However, the change in technology might also have negative impact on skills shortages. The existing workers may not familiar and may not have the skills to work with the new technology. Therefore, the introduction of new technology may induce unemployment as the low skilled workers are replaced by skilled workers familiar with the new technology (BRTE, 2006).

While such policies may well be worthwhile in their own right, again they can only comprise part of the solution. Even large increases in age-specific participation rates could only claw back part of the decline in aggregate participation. And GDP is unlikely to increase by the same proportion as aggregate participation rates, because on average 'new' participants typically acquire lower productivity jobs and work fewer hours. A future reform agenda to enhance Australia's productivity performance needs to be wide-ranging, including economic and social infrastructure, labour markets, taxation, natural resource management, innovation policy and regulatory processes

\section{Conclusion}

Australia is sparsely populated and labour requirements in the future look daunting if current policies are poorly crafted. It is important to acknowledge that various policies meant to address labour supply some structural issues need to be considered. For instance, investing in technologies, technological diffusion benefits a country if specific and technological workers exist as well as fitting a country's comparative advantage. However, Australia must approach this problem through a multifaceted approach that recognises current challenges and future threats. Extending retirement age might be a short run solution while investment in education and technology offer long-term solutions.

\section{References}

[1] Australian Bureau of Statistics 2008, Labour Force Statistics, Canberra.

[2] BRTE (Bureau of Transport and Regional Economics) 2006, Skill Shortages in Australia's Regions, Canberra.

[3] Judy, R and C. SnD'Amico 1997, Workforce 2020, Work and Workers in the 21 Century. Indianapolis: Hudson Institute.

[4] McDonald, Peter and Rebecca Kippen 2001, "Labor Supply Prospects in 16 Developed Countries, 2000-2050", Population and Development Review, 27(1) March 2001, pp.1-32. 
[5] McDonald, Peter and Glenn Withers 2008, Population and Australia's Future Labour Force, Canberra: The Academy of Social Sciences in Australia.

[6] Miracle, Marvin P. and Sara S. Berry 1970, "Migrant Labour and Economic Development", Oxford Economic Papers, viewed on 26 April 2008, <oep. oxfordjournals.org/cgi/reprint/22/1/86.pdf>

[7] Mitchell, William and Victor Quirk 2005, Skills shortages in Australia: Concepts and Reality, Centre of Full Employment and Equity, The University of Newcastle, Australia, viewed on 20 April 2008, <e1.newcastle.edu.au/coffee/pubs/wp/2005/05-16.pdf>

[8] OECD (Organisation for Economic Cooperation and Development) 1995, The Transition from Work to Retirement, Social Policy Studies, no. 16, Paris.

[9] _ 1994, OECD Jobs Study: Evidence and Explanations, OECD, Paris.

[10] Productivity Commission 2005, Economic Implications of an Ageing Australia, Research Report, Canberra.

[11] Romer, GivenNamePaul, M. 1987, 'Crazy explanations for the productivity slowdown', NBER Macroeconomics Annual, pp. 163-202.

[12] GivenNameRoy, R., SnHenson, H. and Lavoie, C. 1996, A Primer on Skill Shortages in Canada, R-96-8E, Human Resources Development Canada, Hull, Canada.

[13] Shah, Chandra and Gerald Burke 2005, 'Skills Shortages: Concepts, Measurement and Policy Responses', Australian Bulletin of Labour, March 2005.

[14] GivenNameTaylor, Philip 2002, New Policies for Older Worker, The Policy Press.

[15] Withers, G. 2002, 'Population ageing and the role of immigration: for the student', The Australian Economic Review, Melbourne Institute of Applied Economic and Social Research, vol. 35, no. 1, pp. 104-12. 